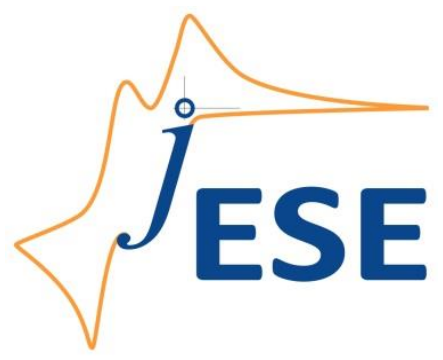

Open Access: ISSN 1847-9286

www.jESE-online.org

Original scientific paper

\title{
Characterization of an HRP-AOX-polyaniline-graphite composite biosensor
}

Ana Carolina O. Santana, Erica F. Southgate, João Paulo B. G. Mendes*, Jo Dweck, Eliana Mosse Alhadeff and Ninoska Isabel Bojorge Ramirez ${ }^{* *, \otimes}$

Escola de Química, Universidade Federal do Rio de Janeiro, Av. Horácio Macedo, 2.030, Centro de Tecnologia, Bloco E, E-203, Cidade Universitária,CEP 21941-909, Rio de Janeiro, Brasil *Instituto de Química, Universidade Federal do Rio de Janeiro, Av. Horácio Macedo, 2.030, Centro de Tecnologia, Bloco A, A-302, Cidade Universitária, CEP 21941-909, Rio de Janeiro, Brasil **Universidade Federal Fluminense, Dep. Engenharia Química e de Petróleo, R. Passo da Pátria, 156, BI E-226, São Domingos, Niterói, CEP 24210-240, Rio de Janeiro, Brasil

¿Corresponding author: E-mail: nbojorge@id.uff.br; Tel.: +55-21-26295598

Received: March 23, 2014; Revised: June 7, 2014; Published: December 6, 2014

\begin{abstract}
Nowadays there is an increasing demand to develop new and robust biosensors in order to detect low concentrations of different chemicals, in practical and small devices, giving fast and confident responses. The electrode material was a polyaniline-graphite-epoxy composite (PANI/GEC). Alcohol oxidase (AOX) and horseradish peroxidase (HRP) enzymes were immobilized and the responses were tested by cyclic voltammetry. The conductivities for the composites of graphite/polyaniline were determined. The cyclic voltammograms allowed detecting ethanol in pure diluted samples in a range from 0.036 to $2.62 \mathrm{M}$. Differential scanning calorimetry (DSC) and thermal gravimetry analysis (TGA) were used to verify the thermal characteristics of the composites $(0,10,20,30$ and $100 \%$ of graphite). The $I_{\max }$ value was determined for the dual enzyme biosensor $(0.0724 \mu \mathrm{A})$, and the $\mathrm{K}^{\mathrm{app}}, \mathrm{m}$ as $1.41 \mathrm{M}$ (with $\left.\mathrm{R}^{2}=0.9912\right)$.
\end{abstract}

\section{Keywords}

Cyclic voltammetry; ethanol; immobilized enzymes; PANI/GCE

\section{Introduction}

Ethanol is the most frequently analyzed aliphatic alcohol and several methods have been developed for its quantitative determination [1-3]. Measurement of alcohol levels in liquors and alcoholic drinks is a common necessity as is clinical analysis of patient tissue samples. The method 
approved by the Association of Official Analytical Chemists [4] for quantitative volumetric determination of alcohol in beer, wine and distilled spirits is pycnometry, which is the most common method for determining solution density. This method is considered as reference and has the advantages of accuracy and no need for comparison against a standard solution. The principal disadvantage is that the methodology is laborious, requiring a significant amount of time for its performance. Another disadvantage is that it requires pre-distillation, generally regarded as the first step in which error is introduced during the process of quantitative detection and analysis [5]. Other more accurate analytical methods include spectrophotometry and chromatographic techniques: gas chromatography (GC) or high performance liquid chromatography (HPLC). However, these methodologies are often less favorable due to high equipment prices and the need for well-trained operators. There is currently a movement toward replacing these methods with low-cost, fast and reliable electrodes working in conjunction with immobilized enzymes [6].

There is a growing need for the development of disposable devices for clinical and/or environmental monitoring. This need has stimulated the development of new technologies and methodologies that can efficiently monitor an increasing number of analytes on site in the environmental field or support clinical diagnoses as quickly and as cheaply as possible; offering even the possibility of on-site field monitoring. Besides selectivity, an analytical device must also be sensitive. In this respect, biosensors have shown great potential in recent years and thus appear to be useful components of effective analytical tools [7-8].

Biosensors that link enzyme catalyzed chemical reactions with amperometric detectors are having a great impact on fields such as environmental monitoring [9-10], analysis of the quality of food and beverages [11-12], biomedical monitoring process [13-14] and biomedicine [15]. These analytical tools, prepared by immobilization of enzymes on an electrode surface, are simple, sensitive and offer a fast response. The main problem that appears in the operation of these devices is the transfer of electrons from the active site of the enzyme to the electrode.

Immobilization of the biological material on the electrode surface constitutes a crucial step in development of the biosensor, since the enzyme's structure must be maintained in order to enable its action on the sample of interest [16-18]. Horseradish peroxidase (HRP) is widely used in enzyme-linked biosensors. However, there are at least two main drawbacks shown by this enzyme: (1) It exhibits a very broad specificity to reduce substrates [19-20], which results in low selectivity of the biosensor; (2) although it displays good stability at room temperature, it is unstable at high temperatures [21-22]. The co-immobilization of alcohol oxidase with horseradish peroxidase is expected to increase the selectivity and amplify the sensitivity of the biosensor for the quantitative determination of ethanol [23-24].

Immobilization of dual enzymes provides an excellent basis for increasing the selectivity, sensitivity and the thermal stability of the biosensor, depending on the strategy adopted for immobilizing the enzymes [15]. The immobilized enzymes may be reused several times or employed in an economical continuous flow path. Dual enzyme-linked sensors are amenable to automation for analytical measurements, scale up of enzymatic biotransformation reactors, or to recover a product with greater purity $[19,25]$. Xie, et al. [26] reported recent advances in enzyme immobilization technologies that enhance enzyme properties such as activity, stability, specificity and reduced inhibition effects. The authors suggest that in the future multi-enzyme sensors based on co-immobilization would be the solution to many of the applications for the biotechnology industry and analytical devices. 
The objective of this study was to characterize a composite-based on PANI / epoxy / graphite and evaluate its performance as a substrate for horseradish peroxidase (HRP) and alcohol oxidase (AOX) enzymes immobilized to an electrode creating a biosensor for ethanol detection. The development of such a method for the immobilization of multiple enzymes is highly attractive, especially for economic reasons because as enzymatic activity decays the support can be regenerated and reloaded with fresh enzyme. In fact, the cost of support is often a primary factor in the overall cost of the immobilized catalyst. In order to build the biosensor a composite prepared with graphite and an electron conductor polymer as polyaniline was studied and characterized in terms of its electrochemical conductance capacity and thermal stability $[18,27]$. We find critical compositions of the material that works with improved sensitivity over a relatively broad range of ethanol concentrations.

\section{Experimental}

\section{Materials}

Horseradish peroxidase (HRP; EC 1.11.1.7) was purchased from Toyobo, Brazil and alcohol oxidase (AOX, EC 1.1.1.1, specific activity of 200 units/mg of protein), graphite powder and polyaniline (emeraldine salt) were purchased from Sigma-Aldrich. For the incorporation of enzymatic solutions, a $2.5 \%(\mathrm{v} / \mathrm{v}$ ) of glutaraldehyde (Sigma-Aldrich) and $1 \mathrm{mg} / \mathrm{mL}$ of protein albumin were used. The ethanol standard solutions were prepared with $0.1 \mathrm{M}$ mono potassium phosphate buffer $(\mathrm{pH}$ 7.0). All reagents were of analytical-reagent grade. All solutions were prepared with distilled water.

\section{Apparatus}

Amperometric measurements were carried out using an AUTOLAB PGSTAT12 (Ecochemie) connected to a personal computer via a serial RS232 port for data acquisition. The obtained amperometric alcohol dual enzyme sensors were evaluated by means of cyclic voltammetry in a three-electrode configuration with $\mathrm{Ag} / \mathrm{AgCl} / \mathrm{KCl}(3 \mathrm{M})$ reference electrode and Pt-wire counter electrode. When not in use, the electrode was stored dry at $4{ }^{\circ} \mathrm{C}$ in a refrigerator.

The thermal properties (thermogravimetric analysis (TGA) and differential scanning calorimetry (DSC)) for the composites of graphite : PANI prepared with 0, 10, 20, 30 and $100 \%$ of graphite were performed by TA Instruments SDT Q600. Analyses were conducted in a $30 \mathrm{~mL} / \mathrm{min}$ flow rate of air atmosphere, with a ramp of $5^{\circ} \mathrm{C} / \mathrm{min}$ from 30 to $800^{\circ} \mathrm{C}$.

The electrical conductivities of the composites pellets were evaluated using the techniques of two electrodes, between which a pellet of known composition of the composite was fixed with the aid of a sleeve of Teflon. The tests were done using a bench meter ICEL Manaus MD - 6700 coupled to a computer. The disks pellets prepared with $0 \%$ and $100 \%$ of pure graphite and composites with 1, 3, 5, 10, 20, 30, 50, 70, 100\% of graphite mixed with PANI were measured. Pure samples of PANI and graphite were also determined.

\section{Preparation and evaluation of the AOX-HRP-based biosensors}

HRP (3.60 g) was dissolved in $30 \mathrm{~mL}$ of $50 \mathrm{mM}$ phosphate buffer (PB, pH 7.0). After filtration and dialysis steps, a $0.133 \mathrm{mg} / \mathrm{mL}$ of HRP solution was mixed with AOX $(47 \mathrm{mg} / \mathrm{mL})$ in buffer $\mathrm{pH}$ 7.0. The $10 \%(\mathrm{w} / \mathrm{v})$ of bovine serum albumin and $2.5 \%(\mathrm{v} / \mathrm{v})$ of glutaraldehyde were also prepared in $50 \mathrm{mM}$ PB ( $\mathrm{pH} 7.0$ ) solution. A $10 \mu \mathrm{L}$ volume of bovine serum albumin and $10 \mu \mathrm{L}$ of glutaraldehyde were deposited on the electrode surface sequentially. The excess of glutar- 
aldehyde was rinsed off with water. Teflon cylindrical electrodes $(5.0 \times 0.7 \mathrm{~cm}$ and $0.13 \mathrm{~cm}$ inside orifice) were used to construct the working dual enzyme biosensor with a $20 \mathrm{~mL}$ electrolytic cell and an $\mathrm{Ag} / \mathrm{AgCl}$ reference electrode and a platinum counter-electrode.

\section{Procedure for immobilization}

The methodology used was the ionic immobilization of AOX and HRP enzymes on the electrode surface constructed using a graphite matrix with polyaniline and an epoxy resin. During the immobilization step, a solution containing $2.5 \%(\mathrm{v} / \mathrm{v})$ glutaraldehyde, $0.5 \%(\mathrm{v} / \mathrm{v})$ BSA and $97 \%(v / v)$ enzyme solution containing $1100 \mu \mathrm{L}$ HRP and $15 \mu \mathrm{L}$ of AOX was deposited on the electrode surface. The electrode was left at $4{ }^{\circ} \mathrm{C}$ for 24 hours [28].

\section{Measurement procedure}

Cyclic voltammetry (CV) measurements on the electrode were performed in a 3-electrode system containing a $\mathrm{Ag} / \mathrm{AgCl} / \mathrm{KCl} 3 \mathrm{M}$ (Microquímica ${ }^{\circledR}$ ) reference electrode, coiled platinum wire (99.99\% pure) mounted at the end of a chemically-resistant epoxy rod as counter electrode in addition to the modified working electrode based on PANI/GCE. The potential was cycled between -400 and $400 \mathrm{mV}$ vs. $\mathrm{Ag} / \mathrm{AgCl}$.

\section{Determination of ethanol in samples}

Ethanol $(95 \%)$ samples $(0.15 \mathrm{~mL})$ were diluted in a $10 \mathrm{~mL}$ flask with $0.1 \mathrm{M}$ mono potassium phosphate buffer solution ( $\mathrm{pH}$ 7.0). Voltammetric determination was carried out by applying the standard addition method. Diluted sample and standard ethanol solution $(0.15 \mu \mathrm{L})$ were added to the voltammetric cell containing $10 \mathrm{~mL}$ of $0.1 \mathrm{M}$ mono potassium phosphate buffer solution $(\mathrm{pH} 7.0)$.

\section{Results and discussion}

\section{Study of differential scanning calorimetry and thermal gravimetry analysis}

The thermal stability of the graphite composite samples was analyzed by TG, derivatived thermogravimetric analysis (DTG) and DSC. Results of TG and DTG analyses are presented in Figure 1. The curves in Figure 1 follow the mass as a function of temperature of composite samples containing $100 \%$ graphite, $20 \%$ graphite and $0 \%$ graphite (100\% polyaniline), respectively. The curve for the composite of Graphite/PANI (red dashed line) shows an intermediate stability between pure samples of Graphite and PANI polymer. The presence of the PANI introduces four decomposition steps. In the first stage, beginning at $150^{\circ} \mathrm{C}$, there is a slow weight loss associated to the release of trapped water or organic solvents in the polymer structure. The second stage of weight loss is observed from $270{ }^{\circ} \mathrm{C}$ to $550{ }^{\circ} \mathrm{C}$ and is attributed to decomposition of the oligomers. The third decay, from $350^{\circ} \mathrm{C}$ to $450^{\circ} \mathrm{C}$, was assigned to the thermal decomposition of the PANI chains. The DTG curves fully support the above mentioned losses. The pure graphite sample decomposes above $600{ }^{\circ} \mathrm{C}$, whereas the $20 \%$ graphite composite presents four degradation steps (three attributed to the pure polyaniline and one to the pure graphite). Similar results were found by Kowner, et al. [29], Bourdo, et al. [30] and Mo, et al. [31].

A linear fitting between the data of polymer content estimated by TG and composition on a dry basis of raw materials in the composites was proposed, showing a good correlation coefficient $\left(R^{2}\right.$ $=0.9811)$. The difference between the values estimated from the correlation with those of the components in the composite has an average value of $-0.1 \%$ with standard deviation of $1.86 \%$. 


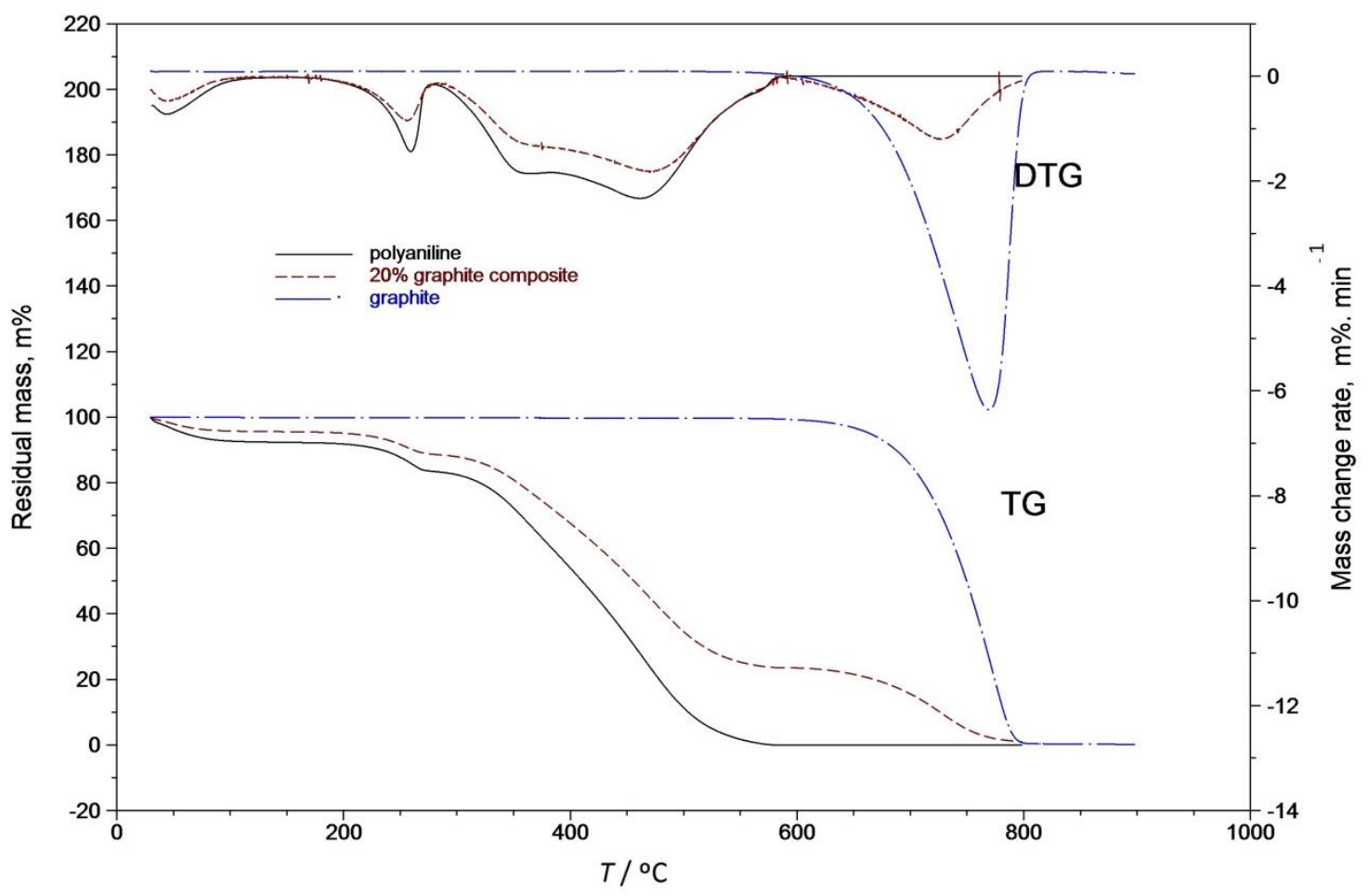

Fig. 1. TG and DTG curves for the samples prepared with 100, 20 and $0 \%$ of graphite.

\section{Conductivity of graphite/PANI composite}

Song and Choi [32] have reported that the most conductive form of PANI is the fully protonated, half-oxidized emeraldine salt form. A decrease in conductivity was observed when the polymer was deprotonated or either fully oxidized or reduced. This work intends to develop a prototype composite-biosensor based on typical PANI that maintains the conductivity. Conductivity values were determined for different concentrations of graphite:polyaniline composites $(1,3,5,10,20,30,50,70,100 \%$ of graphite) and for the pure alcohol oxidase. As shown in Figure 2 an increase in the conductivity of the composite samples was observed.

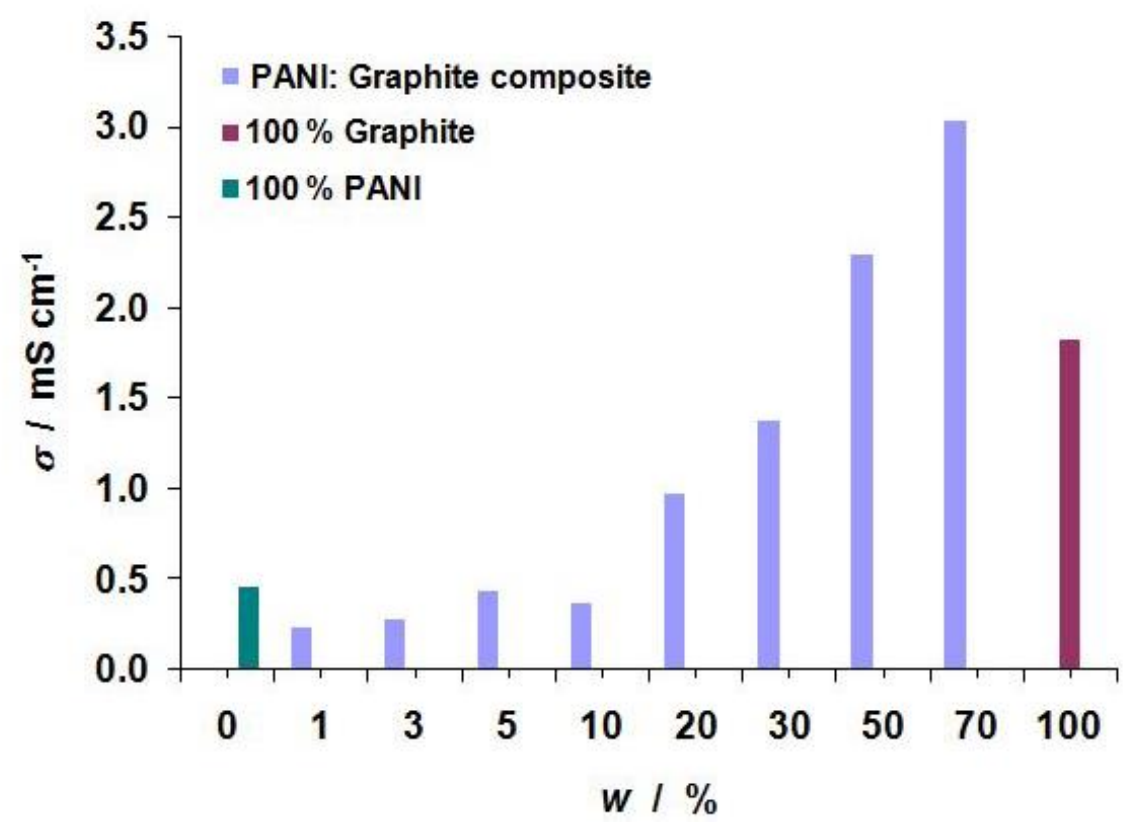

Fig. 2. Electrical conductivities of PANI/GEC as a function of graphite concentration in the composites. Also shown are samples with $100 \%$ PANI (green bar) and $100 \%$ graphite (red bar). 
This is probably due to synergistic effects of mixing the conductive polymer PANI and graphite powder. The mixture better supports electron transfer and, consequently, displays enhanced electrical conductivity. The conductivity values determined for the pure samples of graphite and PANI were $1.82 \times 10^{-3} \mathrm{~S} / \mathrm{cm}$ and $4.64 \times 10^{-4} \mathrm{~S} / \mathrm{cm}$, respectively. The maximum value was obtained with the 70 : 30 (graphite:PANI) composite; higher than the value measured for the $100 \%$ graphite sample. For the composites prepared with 1 to $10 \%$ of graphite, there were not any significant variations in conductivity. A linear relationship between graphite content and conductivity was observed from 20 to $70 \%$ with the conductivity values for 50 to $70 \%$ of graphite surpassing those for the $100 \%$ graphite sample. Mo et al. [31] has detected an increase in the electrical conductivity as a function of graphite nanosheet content in a composite prepared with graphite nanosheets and PANI. Bourdo et al. [30] also found similar behavior for pure PANI and graphite samples and for PANI/graphite composites. In the present study, the $30 \%$ PANI composite compound was employed due to the improved performance of its electrical response.

\section{Electrochemical behaviour of the biosensor}

The biosensor bi-enzymatic HRP/AOX was characterized using cyclic voltammetry to demonstrate the electrochemical performance of the system. Figure 3 shows the cyclic voltammograms obtained from 5 to $150 \mathrm{mV} \mathrm{s}^{-1}$ in a solution of $1 \mathrm{mM} \mathrm{K}{ }_{4} \mathrm{Fe}(\mathrm{CN})_{6}$ mixture in $0.1 \mathrm{M} \mathrm{KCl}$ and phosphate buffer $\mathrm{pH}$ 7.0. The peaks currents of the $\mathrm{CVs}$ indicating quasi-reversible processes between $\mathrm{Fe}(\mathrm{CN})_{6}{ }^{4-} / \mathrm{Fe}(\mathrm{CN})_{6}{ }^{3-}$ couple and the electrodes at the faster scan rates Each curve has the same form but it is apparent that the total current increases with increasing scan rate. This again can be rationalized by considering the size of the diffusion layer and the time taken to record the scan. Clearly the voltammogram will be slower to record as the scan rate is decreased. Hence the size of the diffusion layer above the electrode surface will be different depending upon the voltage scan rate used. In spite of that, working with lower scan rates a well-defined cathodic peak and a small anodic could be identified, and the scan rate of $10 \mathrm{mV} \mathrm{s}^{-1}$ applied to analyze the ethanol samples. So, the best quality voltammogram was obtained working with a scan rate of $10 \mathrm{mV} \mathrm{s}^{-1}$. Therefore, that was the scan rate applied to analyze the ethanol samples

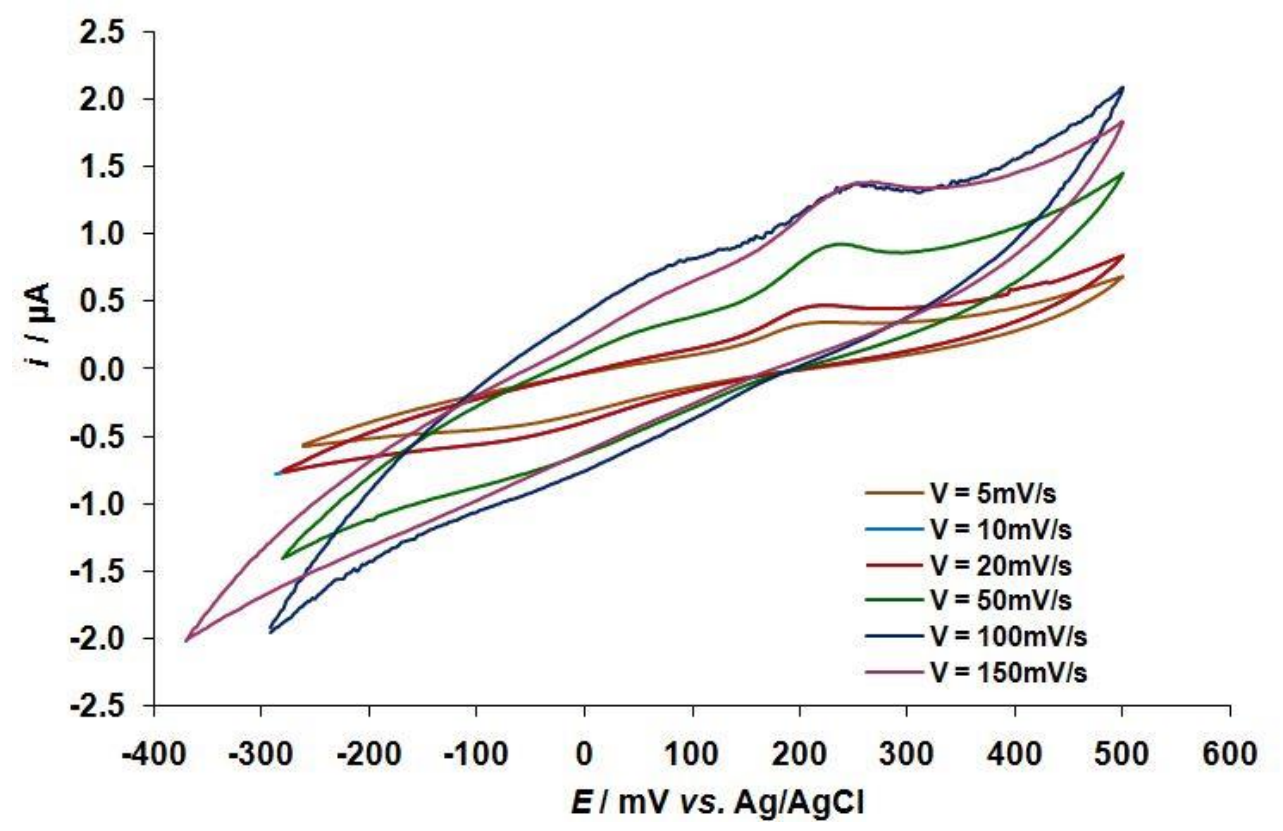

Fig. 3. Cyclic voltammograms of the AOX/HRP/Graphite/PANI in $0.1 \mathrm{MPBS}, \mathrm{pH} 7.0$ at various scan rates (from inner to outer curves: 5, 10, 20, 50, 100, $150 \mathrm{mV} \mathrm{s}^{-1}$ ). 
Figure 4 shows shows the current intensity for the calibration curve changed between $0.61 \mathrm{~mA}$ $(0.316 \mathrm{M})$ to $0.25 \mathrm{~mA}(2.62 \mathrm{M})$ The concentration range of standard ethanol solutions used in the electrochemical measurements was $0.316-2.62 \mathrm{M}\left(R^{2}=0.991\right)$. This clearly demonstrates that the current density reduces linearly with increased ethanol concentration in the samples. This is attributed to an inhibition of the enzyme. The effect is especially evident at the higher ethanol concentrations, probably due to the reaction end-products (acetaldehyde) or external mass transfer limitations. A similar behavior was reported for AOX and HRP that was covalently immobilized on controlled pore glass [23]. However, that study showed that all the supports exhibited less than $20 \%$ of the specific activity of the free enzyme, as a consequence of conformational changes in the 3-D structure of the protein caused by the covalent binding of AOX to the supports. In this work the enzymes were immobilized by adsorption, which is less aggressive than the covalent immobilization. However, the enzyme may be coupled to the support in a way that hinders the access of substrates to the active center, promoting the mass transfer limitations. The amperometric response exhibited by the different immobilized AOX preparations was also very similar although the highest value was obtained when the support was activated using glutaraldehyde in phosphate buffer pH 7. Sirkar, et al. [33] observed an increase in the current density ( $60 \%)$ of the electrochemical biosensor response for a multilayer nanocomposite thin film using glutaraldehyde as a crosslinking agent in a trial for stabilizing the structure. The authors proposed that arginine and lysine residues of the enzyme react with amines present on the redox polymer and, as a consequence, the activity was maintained near $100 \%$ for three weeks.

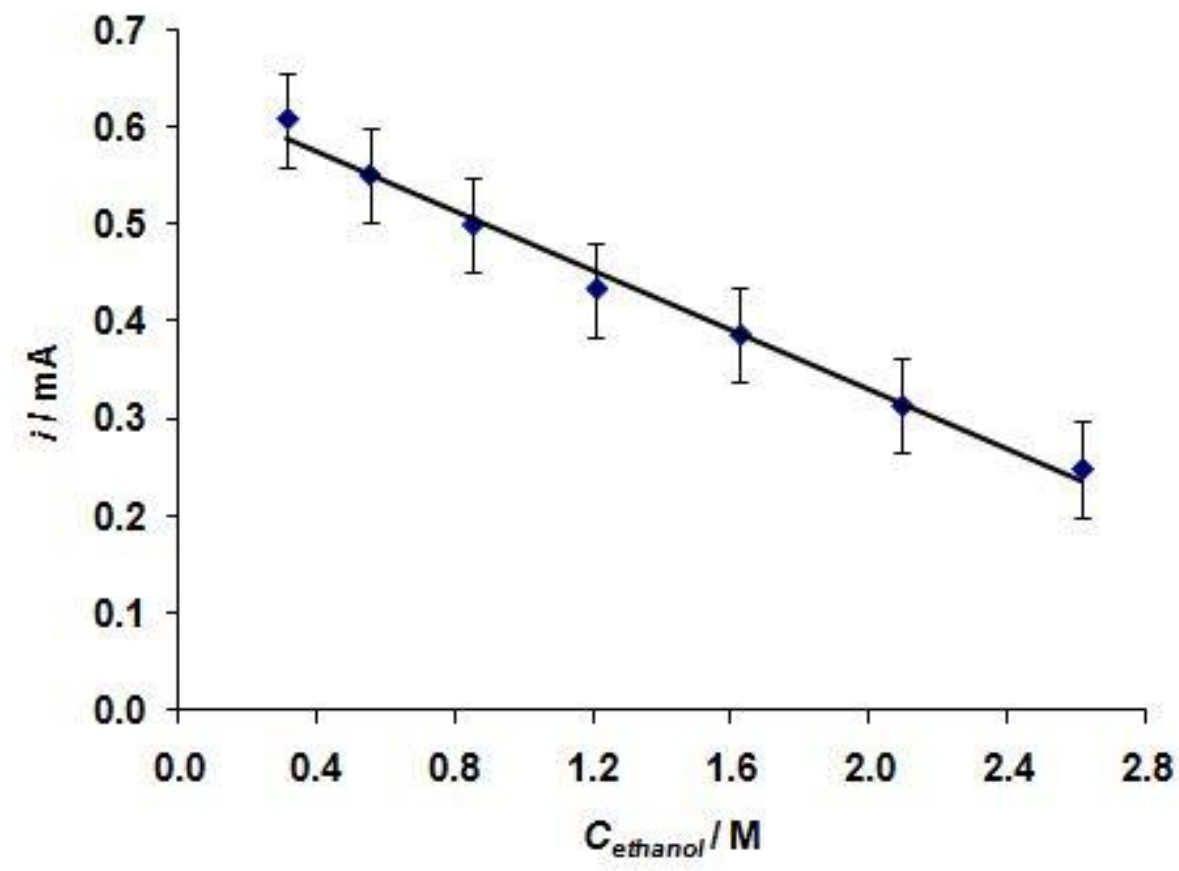

Fig. 4. Ethanol biosensor calibration curve. Scan rate $10 \mathrm{mV} \mathrm{s}^{-1 .}$ ( $n=$ four measurements).

Wu, et al. [34] reported an inverse calibration curve for oxygen consumption by a sensitive ethanol biosensor nanocomposite of carbon nanofiber with immobilized ADH. They observed decreased oxygen consumption with the increase of ethanol concentration in the sample. Chronoamperometric curves showed a decreasing response, upon addition of ethanol aliquots $(0-112 \mu \mathrm{M})$ to static air-saturated pH 7.0 phosphate buffer saline. Wen, et al. [35] reported an ethanol biosensor constructed with alcohol oxidase/chitosan immobilized eggshell membrane and a commercial oxygen sensor. Those measurements were based on the depletion of dissolved 
oxygen upon exposure to ethanol solution (0.15-0.75 mM). Al-Mhanna and Hueber [36] reported an economic system that worked with one enzyme in a differential $\mathrm{pH}$ measurement device for alcohol oxidase and $\beta$-nicotinamide adenine dinucleotide $\left(\mathrm{NADH}^{+}\right)$reaction and obtained a logarithmic curve for ethanol concentrations against change in $\mathrm{pH}$ for standard samples. These authors described an inverse correlation between the signal response and the analyte concentration for the indirect detection measurements working with a wide range of ethanol standard concentration solutions $(17.14 \mu \mathrm{M}-17.14 \mathrm{M})$.

Mackey, et al. [37] optimized the proportion of dual enzyme horseradish peroxidase:glucose oxidase biosensor working with ratios of $1: 7$ to $7: 1$, immobilized on a polyanilinepolyvinylsulphonate modified screen-printed carbon paste electrode and identified the proportion that produced the best response signal was $1: 1$. Rondeau, et al. [38] identified the optimal proportion of two enzymes in the biosensor composite by monitoring electrical response signals to establish idealized conditions for glucose oxidase : horseradish peroxidase immobilized with a modified carbon paste for in order to increase the selectivity, sensitivity, accuracy and stability [38]. The intensity of the electrochemical signal response was analyzed by Alpat and Telefoncu [39] who measured the amount of alcohol dehydrogenase immobilized on the electrode surface (47.1 to $200 \mathrm{U} \mathrm{cm}^{-2}$ ) and found that the linear response was between $0.01 \mathrm{mM}$ and $0.04 \mathrm{mM}$ for $117.6 \mathrm{U} \mathrm{cm}^{-2}$.

Nicell and Wright [40] reported the dependence of horseradish peroxidase activity over a wide range of hydrogen peroxide concentrations. They observed an increase in the inhibitory effect on the enzyme catalytic activity. The static procedures of the electrochemical measurements of this work for the ethanol concentration solutions $(0.330-2.62 \mathrm{M})$ probably promotes an increase of the peroxide hydrogen concentration in the electrolytic cell, and hence the inhibition of the HRP.

Yotova and Medhat [41] reported the inhibition effect in a multi-enzyme immobilized biosensor system constructed to analyze residue from pesticides with acetylcholinesterase and choline oxidase. The relative inhibition percentage of each measurement was calculated using the following equation:

$$
I, \%=\frac{I p c_{0}-I p c}{I p c_{0}} 100
$$

where $I$ is the relative inhibition; $I p c_{0}$ is the initial inhibited cathode current intensity measured for the lower ethanol concentration and $I p c$ the inhibited cathode current intensity determined for each sample. Assuming a possible inhibition effect on the cyclic voltammetric response signal with the increase of the ethanol concentration in the sample, this treatment was adopted for this work. A linear correlation was observed, confirming the inhibitory effect of the ethanol on the enzyme.

Amine, et al. [42] published a review that discusses horseradish peroxidase among the enzymes that could be used for inhibition-based biosensors applied for food safety and environmental monitoring. Kuusk and Rinken [43] classified the carbaril inhibition of tyrosinase biosensor by excess substrate and considered the reasons behind their inability to determine low carbaryl concentrations by a classical steady state kinetic approach. The $K_{\mathrm{m}}$ and $I_{\max }$ kinetics parameters were calculated from Lineweaver-Burk plots by using the relative inhibition values as described in equation 2:

$$
\frac{1}{R I}=\frac{K_{\mathrm{m}}^{\mathrm{app}}}{R I_{\max }} \frac{1}{C_{\text {ethanol }}}+\frac{1}{R I_{\max }}
$$


where $1 / C_{\text {ethanol }}$ is the concentration of the ethanol in the solution sample, $R I$ and $R I_{\max }$ represent the initial and the maximum relative inhibition current, respectively, and $K^{\text {app }}{ }_{m}$ is the apparent Michaelis constant.

The Lineweaver-Burk plot for the dual enzyme AOX-HRP biosensor showing $1 / /$ versus $1 / C_{\text {ethanol }}$ is illustrated in Figure 5.

The $I_{\max }$ value determined considering the inhibition effect on the dual enzyme biosensor was $0.0724 \mu \mathrm{A}$, and the $K^{\mathrm{ppp}}{ }_{m}$ was $1.41 \mathrm{M}\left(\mathrm{R}^{2}=0.9912\right)$.

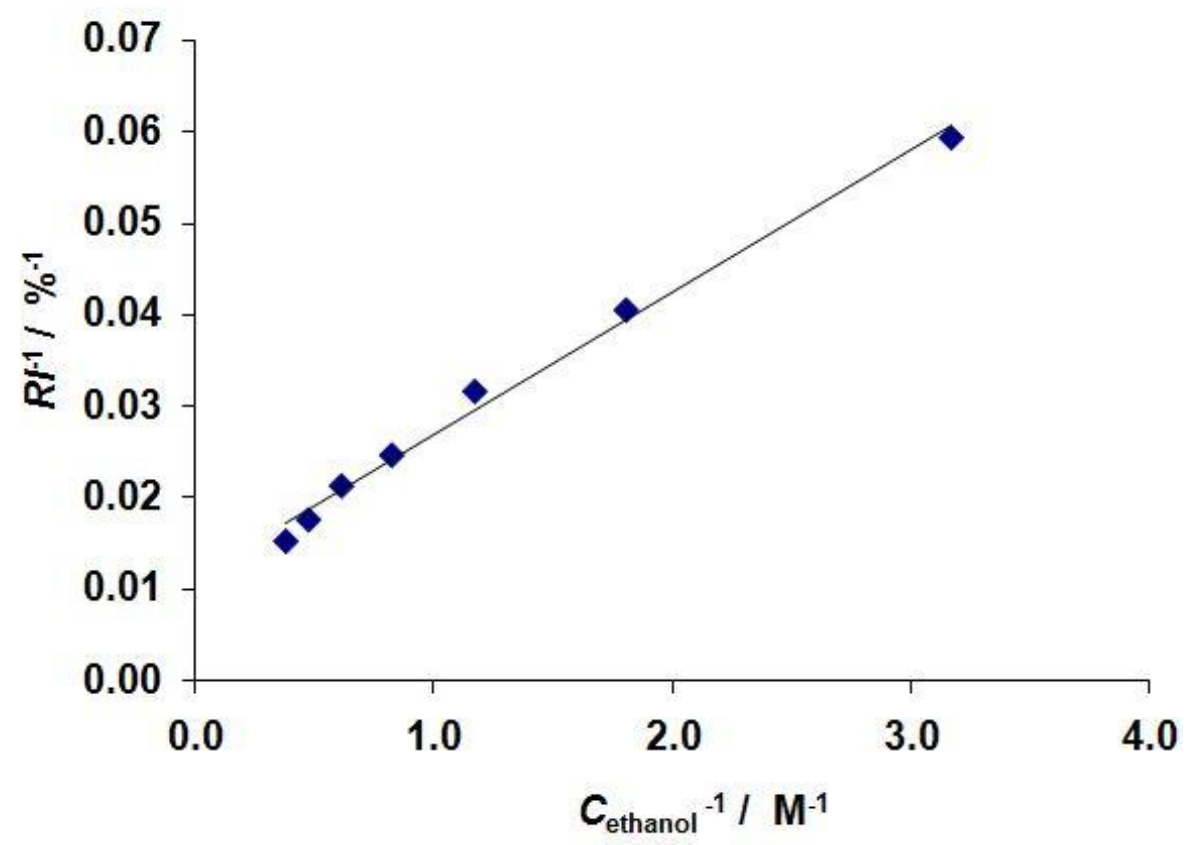

Fig. 5. Line-weaver-Burk plot for the bienzimatic AOD-HRP biosensor for different ethanol concentration

Table 1 shows the analytical performance of the proposed ethanol biosensor towards ethanol detection compared with various electrochemical biosensors modified for dual enzymes that also reported $K^{\mathrm{app}},_{m}$ and $I_{\max }$. Despite the low affinity for substrate observed in this work, the sensitivity was higher when compared with those determined for both redox hydrogel dual enzyme films previously reported in the literature [44-45]. This suggests that the linear range and detection limit of the proposed ethanol biosensor mentioned above appear to be beneficial compared to other previously reported modified electrodes.

Table 1. Comparison of analytical characteristics of ethanol dual enzyme biosensors.

\begin{tabular}{|c|c|c|c|c|c|}
\hline Film/Composite/Enzymes & I.D. $/ \mathrm{cm}$ & $K^{\mathrm{app}},{ }_{\mathrm{m}} / \mathrm{mM}$ & $I \max / \mathrm{nA}$ & Sensitivity, $\mathrm{nA} / \mu \mathrm{M}$ & Reference \\
\hline $\mathrm{HRP}+\mathrm{AOX}+\mathrm{PVI}-\mathrm{Os}$ & 0.305 & 4.71 & 813.95 & 0.17 & {$[44]$} \\
\hline $\mathrm{HRP} / \mathrm{PVI}{ }_{10}-\mathrm{Os} / \mathrm{PEG}-\mathrm{DGE} / \mathrm{AOX} / \mathrm{CP} 5$ & 0.305 & $9.6 \pm 0.3$ & $572 \pm 7$ & 0.06 & {$[45]$} \\
\hline PANI-GEC/HRP/BSA/AOX & 0.130 & 1.410 & 72.4 & 51.3 & This work \\
\hline
\end{tabular}

I.D. - internal diameter; PVI - Poly(vinyl-imidazole; $P V I_{10}-O s$ - redox hydrogel synthesized;

PEG-DGE - Poly(ethylene glycol) (400) diglycidyl ether; CP5 - electrodeposition polymer;

Os - complex: redox polymers synthesized (4,4'dimethylbipyridine); PANI-GEC: polyaniline in Graphite epoxy composite; $B S A$ - Bovine serum albumin. The applied potentials for all configurations are $-50 \mathrm{mV} v \mathrm{vg}$. $\mathrm{AgCl}$. 


\section{Conclusions}

The composite material prepared from differing proportions of graphite and PANI displayed enhancement in the conductivity for compositions of less than $20 \%$ graphite and a synergistic effect that increased its response for mixtures with more than $50 \%$ of graphite. The thermal analysis techniques applied to characterize the prepared composites showed a good agreement with the original proposed formula composition. The electrochemical results confirm that it is possible to detect ethanol with this biosensor in the ethanol concentration range of 0.316 to $2.62 \mathrm{~mol} \mathrm{~L}^{-1}$ limited by a significant inhibition effect observed in the enzyme.

Acknowledgements: Thanks to Toyobo of Brazil (enzyme horseradish peroxidase) and CNPq support from the Announcement Universal - 2008/2010 and PIBIC.

\section{References}

[1] ASTM. D5501-12 Standard Test Method, 100 Barr Harbor Drive, West Conshohocken, PA, USA, ASTM International (2012).

[2] G. Hall, W. M. Reuter, HPLC Analysis for the Monitoring of Fermentation Broth During Ethanol Production as a Biofuel, www.perkinelmer.com/pdfs/downloads/abr ethanolasbiofuelbyhplcappbrief.pdf (17.07. 2014).

[3] K. Schugerl, J. Biotechnol. 85 (2001)149-173.

[4] W. Horwitz, Official methods of Analysis of AOAC International. Gaithersburg, Maryland 20877-2417, USA, AOAC International (2005).

[5] M. L. Wang, J. T. Wang, Y. M. Choong, Food Chem. 86 (2004) 609-615.

[6] L. Cao, Introduction: Immobilized Enzymes: Past, Present and Prospects. In: Carrier-bound Immobilized Enzymes: Principles, Application and Design. KGaA, Weinheim, WILEY-VCH Verlag GmbH \& Co, 2005, p.100.

[7] H. Nakamura, I. Karube, Anal. Bioanal. Chem. 377(3) (2003) 446-468.

[8] A. P. F. Turner, Chem. Soc. Rev. 42(8) (2013) 3184-3196.

[9] R. W. Bogue, Sensor 4 (2003) 302-310.

[10] A. K. Wanekaya, W. Chen, A. Mulchandani, J. Environ. Monit. 10 (2008) 703-712.

[11] M. C. Blanco-Lopez, M. J. Lobo-Castanon, A. J. Miranda-Ordieres, J. Chem. Education 84(4) (2007) 677-678.

[12] M. F. Barroso, M. F. C. Delerue-Matos, M. B. P. P. Oliveira, Food Chem. 132 (2012), 10551062.

[13] N. I. Bojorge-Ramírez, A. M. Salgado, B. Valdman, Assay Drug Dev. Technol. 5(5) (2007) 673682.

[14] M. S. Belluzo, M. E. Ribone, C. M. Lagier, Sensors 8 (2008) 1366-1399.

[15] J. Liu, J. Wang, Biotech. Applied Biochem. 30 (1999) 177-193.

[16] N. I. Bojorge-Ramirez, A. M. Salgado, B. Valdman, Brazilian J. Chem. Eng. 26(2) (2009) $227-$ 249.

[17] E. M. Alhadeff, A. M. Salgado, O. Cós, N. Pereira Jr., B. Valdman, F. Valero, Appl. Biochem. Biotech. 146 (2008) 129-136.

[18] N. I. Bojorge-Ramírez, E. Alhadeff, Graphite-Composites Alternatives for Electrochemical Biosensor. In: Metal, Ceramic and Polymeric Composites for Various Uses, Uses. J. Cuppoletti: (2011) p. 684.

[19] N. C. Veitch, Phytochemistry 65 (2004) 249-259.

[20] A. M. Azevedo, V. C. Martins, D. M. Prazeres, J. Vojinovic, J. M. S. Cabral, L. P. Fonseca, Biotechnol. Annu. Rev. 9 (2003) 199-247.

[21] K. Chattopadhayay, S. Mazumdar, Biochemistry 39 (2000) 263-270. 
[22] A. S. L. Carvalho, E. Pinto e Melo, B. S. Ferreira, M.T. Neves-Petersen, S. B. Petersen, M.R. Aires-Barros, Arch. Biochem. Biophys. 415 (2003) 257 - 267.

[23] A. M. Azevedo, J. M. S. Cabral, T. D. Gibson, L. P. Fonseca, J. Mol. Catal. B-Enzym. 28(2-3) (2004) 45-53.

[24] A. M. Azevedo, D. M. Prazeres, J. M. S. Cabral, L. P. Fonseca, Biosens. Bioeletron. 21 (2005) 231-247.

[25] S. Datta, L. R. Christena, Y. R. S. Rajaram, Biotech. 3(1) (2013) 1- 9.

[26] T. Xie, A. Wang, L. Huang, H. Li, Z. Chen, Q. Wang, X. Yin, Afr. J. Biotechnol. 8(19) (2009) 4724-4733.

[27] J. Dweck, B.F. Andrade, E.E.C. Monteiro, R. Fischer, J. Therm. Anal. Calorim. 67 (2002) 321326.

[28] R. S. Lima, G. S. Nunes, T. Noguer, J. Marty, Quím. Nova 30(1) (2007) 9-17.

[29] S. Konwer, J. P. Gogoi, A. Kalita, S.K. Dolui, J. Mater. Sci.: Mater. Electron. 22 (2011) 1154 1161.

[30] S. Bourdo, B. A. Warford, T. Viswanathan, J. Solid State Chem. 196 (2012) 309-313.

[31] Z. Mo, H. Shi, G. Niu, Z. Zhao, Y. Wu, J. App. Polymer Sci. 112 (2009) 573-577.

[32] E. Song, J.W. Choi, Nanomaterials 3, (2013) 498-523.

[33] K. Sirkar, A. M. Revzin, V. Pishko, Anal. Chem. 72, (2000) 2930-2936.

[34] L. Wu, J. Lei, X. Zhang, H. Ju, Biosens. Bioelectron. 24 (2008) 644-649.

[35] G. Wen, Y. Zhang, S. Shuang, C. Dong, M. M. F. Choi, Biosens. Bioelectron. 23 (2007) 121129.

[36] N. M. M. Al-Mhanna, H. Huebner, Int. J. Chem. 3(1) (2011) 47-56.

[37] D. Mackey, A. Killard, A. Ambrosi, M. Smyth, Sens. Actuator B-Chem. 122 (2007) 395-402.

[38] A. Rondeau, N. Larsson, M. Boujtita, L. Gorton, N. El Murr, Analysis 27 (1999) 649-656.

[39] S. Alpat, A. Telefoncu, Sensors 10, (2010) 748-764.

[40] J. A. Nicell and H. Wright, Enzyme Microb. Technol. 21(4) (1997) 302-310.

[41] L. Yotova, N. Medhat, Int. J. Bioautomation 15(4) (2011) 267-276.

[42] Amine A., H. Mohammadi, I. Bourais, G Palleschi, Biosens. Bioelectron. 21 (2006) 1405 -142.

[43] E. Kuusk, T. Rinken, Enzyme Microb. Technol. 34 (2004) 657-661.

[44] J. Castillo, S. Gáspar, I., Sakharov, E. Csöregi, Biosens. Bioelectron. 18 (2003) 705-714.

[45] I. S. Alpeeva, A. Vilkanauskyte, B. Ngounou, E. Csöregi, I. Y. Sakharov, M. W. Gonchar, Microchim. Acta 152 21-27 (2005).

(C) 2014 by the authors; licensee IAPC, Zagreb, Croatia. This article is an open-access article distributed under the terms and conditions of the Creative Commons Attribution license (http://creativecommons.org/licenses/by/4.0/) (cc) EY 